\title{
Experimental Shear Behaviour of Rammed Earth Strengthened with a TRM-Based Compatible Technique
}

\author{
Antonio Romanazzi ${ }^{1, a^{*}}$, Michiel Van Gorp ${ }^{2, b}$, Daniel V. Oliveira ${ }^{1, c}$, \\ Rui A. Silva ${ }^{1, d}$ and Els Verstrynge ${ }^{2, e}$
}

${ }^{1}$ ISISE, Institute of Science and Innovation for Bio-Sustainability (IB-S), University of Minho, Department of Civil Engineering, Guimarães, Portugal

${ }^{2} \mathrm{KU}$ Leuven, Department of Civil Engineering, Leuven, Belgium

aaromanazzi89@gmail.com, bmichiel.vangorp@outlook.com, cdanvco@civil.uminho.pt, druisilva@civil.uminho.pt, eels.verstrynge@kuleuven.be

Keywords: Diagonal compression test, shear strength, textile reinforced mortar, digital image correlation.

\begin{abstract}
Earthen constructions are spread worldwide, not only as architectural heritage but also as new buildings, in which a total of around one fourth of the global population is estimated to live in. Among the different raw earth techniques, rammed earth was widely used to build vernacular dwellings in different regions. Despite the raising awareness for the high seismic hazard, recognized seismic vulnerability and high seismic exposure associated with earthen structures, the reduction of their seismic risk has been a topic insufficiently addressed. In general, the seismic vulnerability of rammed earth structures is due to poor connections between structural elements (walls and floors), high self-weight and low strength of the material. Hence, a TRM-based strengthening technique is proposed to improve their seismic capacity. To estimate the enhancement of the in-plane performance achieved with the TRM, an experimental program was conducted. Rammed earth wallets were tested under diagonal compression considering their unstrengthened and strengthened condition. The TRM strengthening was performed by embedding a glass fibre mesh (GRE) or a nylon mesh $(N R E)$ in a compatible earth-based mortar. In general, the proposed TRM-based strengthening seems to improve the shear behaviour of rammed earth by enhancing the shear strength and promoting stress distribution after cracking, while no significant influence on the shear modulus of rammed earth seems to occur.
\end{abstract}

\section{Introduction}

Nowadays, around one fourth of the global population is estimated to live in earthen constructions, while about $10 \%$ of UNESCO World Heritage is built with earth [1][2]. Among the different building techniques based on the use of raw earth, rammed earth (or "taipa" in Portugal, "pise" in France or "terra battuta" in Italy) was widely used for monuments and affordable dwellings, as for instance in Alentejo (Southern Portugal) [3][4]. This building technique consists in compacting moistened soil within a wooden formwork, whose typical dimensions are of about 1.7-3.0 $\times 1.0 \times 0.5 \mathrm{~m}^{3}$ (length $\mathrm{x}$ height $\mathrm{x}$ width). The compaction is performed manually by layers until completing a block, which is subsequently demoulded. The formwork is then reused to build the subsequent block until completion of a course. This process is repeated to complete the next courses until the desired height of the wall is achieved [1]. Earthen buildings are also well known for their high seismic risk, which results from the high seismic hazard where they are located, high seismic vulnerability of the structures and the high seismic exposure (e.g. earthquake in Bam 2003, Pisco 2007, Maule 2010) [5][6]. The seismic vulnerability of rammed earth constructions is in general due to low mechanical properties of the material, high self-weight and poor connections between structural elements, which compromise the in-plane and out-of-plane response of the walls [7]. The strengthening with textile reinforced mortars (TRM) has been demonstrated to be an efficient solution to reduce the seismic vulnerability of masonry buildings [8][9]. In the case of rammed earth 
dwellings, it is also expected to constitute an adequate strengthening solution due to its low selfweight, high tensile strength and ductility. TRM is a composite made with an inorganic matrix, whose role is bonding the fiber, conferring compressive strength and granting geometrical stability, while the embedded mesh provides tensile strength and distributes stresses through adhesion and friction within the matrix [8][10][11]. Furthermore, the fact that TRM can be an affordable solution is a key aspect considering the low-cost of earthen buildings. The use of TRM in adobe constructions was studied in a wide experimental programme in Peru, where synthetic meshes were externally applied by means of earth-based mortars, revealing to be an efficient solution for in-plane and out-of-plane loads [11]-[13]. Research on TRM strengthening for rammed earth buildings started recently and the first outcomes prove enhancement of the overall seismic capacity as that achieved in the case of adobe structures [6][14][15]. Nevertheless, the "compatibility" of the strengthening system is overlooked, which is required to ensure long-term effectiveness and durability of the interventions [16]. The shear behavior of unreinforced rammed earth wallets was investigated by means of diagonal compression tests [17]. The results showed an early peak shear stress which is related to the cohesion of the clay fraction. Afterwards, shear hardening is developed by friction and interlocking of the aggregates. Delamination at the interface between the layers was also observed. About the characterization of TRM components for rammed earth dwellings, exploratory studies on different earth-based mortars and meshes have been already conducted [18][19]. A nylon mesh and a glass fiber mesh were found to be suitable because of their geometrical properties and workability, while unstabilized earth-based mortar showed adequate shrinkage and strength properties. Nevertheless, no investigations have been conducted so far on the in-plane response of rammed earth strengthened with TRM. Thus, an experimental program on the shear behavior of unstrengthened and TRM-strengthened rammed earth wallets was undertaken within the framework of the research project SafEarth. Firstly, the mechanical properties of each material component were investigated, namely of the rammed earth, earth-based mortar and two meshes (glass fiber and nylon). Afterwards, the diagonal compression tests were performed on unstrengthened $(U R E)$, glass fiber mesh strengthened $(G R E)$ and nylon mesh strengthened (NRE) rammed earth wallets. Furthermore, digital image correlation $(D I C)$ was implemented to analyse the crack pattern development.

\section{Materials (soil, earth mortar, meshes and rammed earth)}

The materials used in this investigation, namely soil, earth-based mortar and meshes were characterized in previous studies [19][20]. The soil was collected from Alentejo and was used to build the rammed earth wallets and compose the mortar. Since the original soil presented excessive clay content, it was corrected by addition in weight of $30 \%$ of coarse sand and $30 \%$ of gravel to $40 \%$ of original soil, achieving then a maximum dry density after compaction $\left(\rho_{d}\right)$ of $2.13 \mathrm{~g} / \mathrm{cm}^{3}$ for an optimum water content $(O W C)$ of $10 \%$, while the liquid limit $(L L)$, plastic limit $(P L)$ and index of plasticity $(I P)$ do not change (see Table 1$)$.

Table 1. Geotechnical properties of the original and corrected soils

\begin{tabular}{ccccccccccc}
\hline Soil & Clay \% & Silt \% & Sand \% & Gravel $\%$ & $\rho_{d}\left(\mathrm{~g} / \mathrm{cm}^{3}\right)$ & OWC $(\%)$ & LL $(\%)$ & PL (\%) & IP (\%) \\
\hline Original & 29 & 32 & 21 & 18 & 1.81 & 18 & 45 & 24 & 21 \\
\hline Corrected & 12 & 13 & 34 & 41 & 2.13 & 10 & 45 & 24 & 21 \\
\hline & $*$ Clay $<0.002 \mathrm{~mm}<$ silt $<0.06 \mathrm{~mm}<$ sand $<2 \mathrm{~mm}<$ gravel \\
$*$ & $\rho_{\mathrm{d}}$ maximum dry density after compaction
\end{tabular}

Table 2 presents the mechanical properties of rammed earth elements and earth mortar in terms of density $\left(\rho_{d}\right)$, compressive strength $\left(f_{c}\right)$, tensile strength $\left(f_{t}\right)$ and elastic modulus $(E)$. Table 3 reports the mechanical and physical characteristics of glass fibre mesh $(G M)$ and nylon mesh $(N M)$ used for strengthening, namely with respect to the cost for unit area $\left(\epsilon / \mathrm{m}^{2}\right)$, mesh aperture $(\mathrm{mmXmm})$, bulk density $(\rho)$, cross section of the single yarn $\left(A_{\text {yarn }}\right)$, linear strength along the main direction $\left(F_{w, p}\right)$, 
tensile strength of the single yarn $\left(f_{t}\right)$, elongation at peak load $\left(\varepsilon_{\text {peak }}\right)$ and elastic modulus of the single yarn $(E)$.

Table 2. Mechanical properties of rammed earth elements and earth mortar.

\begin{tabular}{ccccc}
\hline Soil & $\rho_{d}\left(\mathrm{~g} / \mathrm{cm}^{3}\right)$ & $f c(\mathrm{MPa})$ & $f t(\mathrm{MPa})$ & $\mathrm{E}(\mathrm{MPa})$ \\
\hline Rammed earth & 2.08 & 1.5 & - & 471 \\
\hline Earth mortar & 1.81 & 0.77 & 0.32 & 1978 \\
\hline
\end{tabular}

Table 3. Mechanical and physical properties of GM and NM.

\begin{tabular}{ccccccccc}
\hline $\begin{array}{c}\text { Type of } \\
\text { mesh }\end{array}$ & $\begin{array}{c}\text { Price } \\
\left(€ / \mathrm{m}^{2}\right)\end{array}$ & $\begin{array}{c}\text { Mesh size } \\
(\mathrm{mmXmm})\end{array}$ & $\begin{array}{c}\rho \\
\left(\mathrm{g} / \mathrm{cm}^{3}\right)\end{array}$ & $\begin{array}{c}\mathrm{A}_{\text {yarn }} \\
\left(\mathrm{mm}^{2}\right)\end{array}$ & $\begin{array}{c}F_{w, p} \\
(\mathrm{kN} / \mathrm{m})\end{array}$ & $\begin{array}{c}f_{t} \\
(\mathrm{MPa})\end{array}$ & $\begin{array}{c}\varepsilon_{\text {peak }} \\
(\mathrm{mm} / \mathrm{mm})\end{array}$ & $\begin{array}{c}E \\
(\mathrm{MPa})\end{array}$ \\
\hline \multirow{2}{*}{$\mathrm{GM}$} & 0.85 & $8 \times 9$ & 1.610 & 0.29 & $\begin{array}{c}18.42 \\
(11 \%)\end{array}$ & $\begin{array}{c}625.80 \\
(11 \%)\end{array}$ & $0.021(10 \%)$ & $\begin{array}{c}31981 \\
(6 \%)\end{array}$ \\
\hline \multirow{2}{*}{$\mathrm{NM}$} & 0.63 & $16 \times 21$ & 0.897 & 0.97 & $\begin{array}{c}3.18 \\
(4 \%)\end{array}$ & $\begin{array}{c}54.37 \\
(4 \%)\end{array}$ & $\begin{array}{c}0.340 \\
(16 \%)\end{array}$ & $\begin{array}{c}361 \\
(4 \%)\end{array}$ \\
\hline
\end{tabular}

\section{Diagonal Compression Tests}

Nine rammed earth wallets were manufactured using the soil mixture referred previously. The addition of water was controlled through the drop ball test, which consists in letting fall a ball of approximately $4 \mathrm{~cm}$ of diameter from a height of $1.5 \mathrm{~m}$. The right amount of water entails the sample to a rupture in a big pyramidal central piece and few pieces around it. Once the test was satisfied, the average water content was determined as $9.4 \%(\mathrm{CoV} 9.6 \%)$, which is a value similar to that obtained from the standard Proctor test. Then, the mixture was compacted manually inside a wooden formwork previously oiled. Each wallet was composed of 9 layers of approximately $61 \mathrm{~mm}$ of thickness each and total dimensions of $550 \times 550 \times 200 \mathrm{~mm}^{3}$ (length $\mathrm{x}$ height $\mathrm{x}$ width). After a drying period of 2 months in laboratory conditions, six specimens (three for each mesh) were strengthened by applying the TRM on both sides. Each surface was firstly scraped and wetted to increase the adherence of the mortar and prevent early water reduction in the mortar. Afterwards, the mesh was applied parallel to the rammed earth surface on a $5 \mathrm{~mm}$ thick coating earth mortar, while setting the main direction of the fabric perpendicular to the layers. A second layer of earth mortar $5 \mathrm{~mm}$ thick was applied to cover the mesh. In order to avoid contact between the testing steel shoes and the mortar coating, the strengthening was applied on a surface smaller than that of the wallet, namely with dimensions of about $500 \times 500 \mathrm{~mm}^{2}$. According with the testing conditions, the specimens were labelled as unstrenghtened (URE), glass fibre mesh strengthened (GRE) and nylon mesh strengthened $(N R E)$ rammed earth wallets. After an aging period of one month in laboratory conditions, each wallet was weighted to compute the bulk density of the only rammed earth, resulting in an average value of $2.14 \mathrm{~g} / \mathrm{cm}^{3}(\mathrm{CoV} 3 \%)$, which is comparable with the that obtained in the standard Proctor test. The displacement controlled diagonal compression tests were performed at rate $2 \mu \mathrm{m} / \mathrm{s}$. Angular steel shoes with free span of $100 \mathrm{~mm}$ were used to set the specimens rotated $45^{\circ}$ and to load them avoiding any punching. The vertical and horizontal displacements were recorded by two linear variable differential transformers (LVDTS) fixed in the middle third of the two diagonals of one side of the wallets, here referred as LVDT_V and LVDT_H respectively (Figure 1a). Since local detachment of the TRM could occur after cracking, the LVDTs where screwed directly in the rammed earth (Figure 1b). Digital image correlation $(D I C)$ was also implemented on the free surface of the wallet, where the stochastic pattern was created with black spots on white background. The pictures were captured each 10s with a SONY $\alpha 600024,7$ megapixel, with 16-50 mm (24-75 mm) - 3.5 lens (Figure 1c). The DIC analysis was performed using GOM Correlate software [21]. It should be noted that the LVDTs detached after the elastic behaviour of the specimens URE_3, GRE_3 and NRE_2, meaning that the strain values obtained in the non-linear stage are unreliable. 


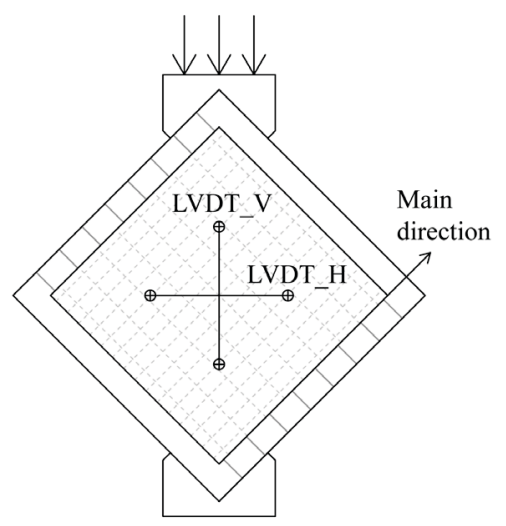

(a)

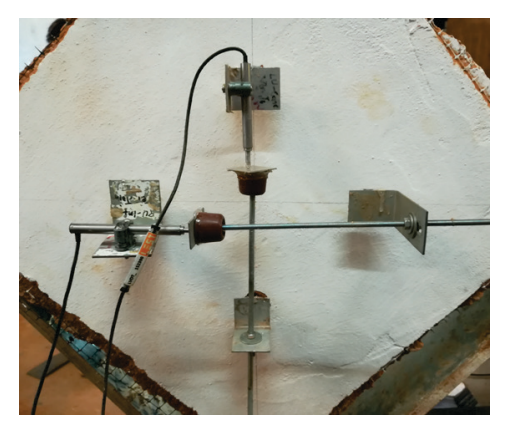

(b)

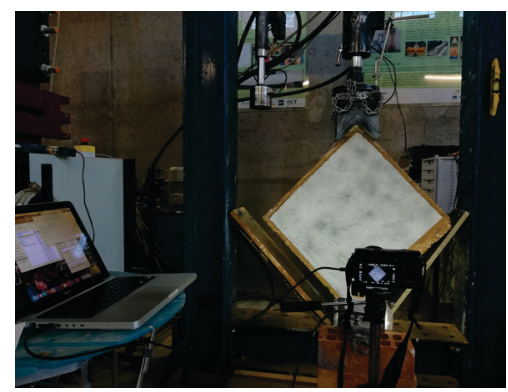

(c)

Figure 1. (a) Scheme of diagonal compression testing setup, (b) disposition of the LVDTs and (c) DIC apparatus.

\section{Experimental Results and Discussion}

The shear stress $(\tau)$ and shear strain $(\gamma)$ were calculated according to ASTM E519 [22] using the information coming from the LVDTs. Figure 2 shows that in general the response is linear elastic up to the first crack. During this phase, the cohesion of the finest component of the rammed earth ensures the strength of wallet. After full propagation of the diagonal crack, the friction and interlocking promoted by the aggregates become the main resisting mechanisms and the behaviour is non-linear until the peak load, which is followed by a somehow stable plateau (Figure 2). Comparing the two strengthening options, the non-linear behaviour up to the shear strength is more evident in case of GRE rather than of NRE. Such response could be ascribed to the distinct stiffness of the embedded mesh. Indeed, the nylon mesh, being more flexible than the glass fiber, required a relatively higher deformation to contribute to improve the shear strength of the wallet.

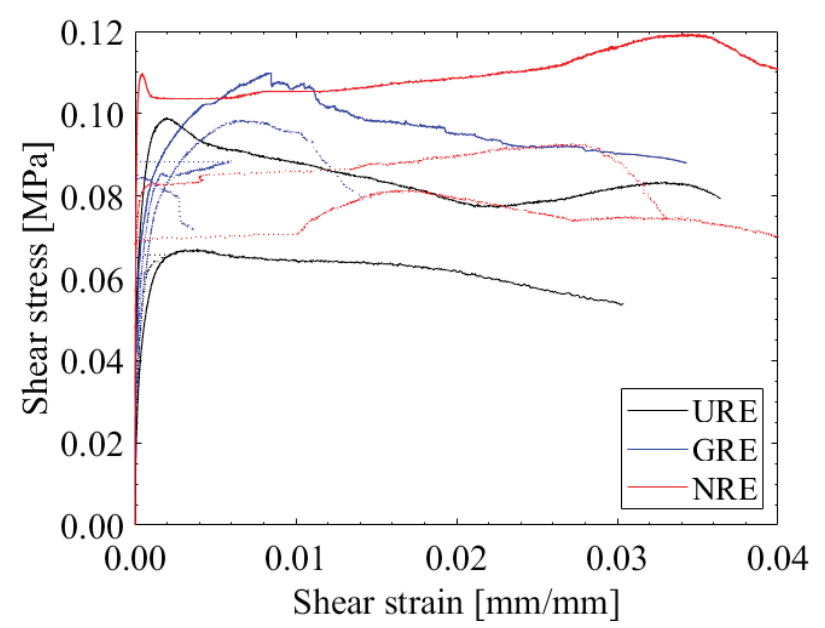

Figure 2. Shear stress-strain curves obtained from the diagonal compression test of URE, GRE and NRE specimens.

The shear strength $\left(\tau_{\max }\right)$, the corresponding shear strain $\left(\gamma_{\tau \max }\right)$ and the ultimate shear strain $\left(\gamma_{u l t}\right)$, referred as the post-peak strain at $80 \%$ of the shear strength, are reported in

Table 4. In both cases, the TRM strengthening enhanced about $25 \%$ the average shear strength $\left(\tau_{\max }\right)$. The shear strain corresponding to the peak load $\left(\gamma_{\tau \max }\right)$ is shown to improve significantly in the case of NRE, but just slightly in GRE case. With respect to the ultimate shear strain $\left(\gamma_{u l t}\right)$, no significant change was observed with the TRM strengthening. 
Table 4. Shear strength and shear strain values obtained from the diagonal compression tests.

\begin{tabular}{cccccccccccc}
\hline Sample & $\begin{array}{c}\tau_{\max } \\
(\mathrm{MPa})\end{array}$ & $\begin{array}{c}\gamma_{\max } \\
(\%)\end{array}$ & $\begin{array}{c}\gamma_{\mathrm{ult}} \\
(\%)\end{array}$ & Sample & $\begin{array}{c}\tau_{\max } \\
(\mathrm{MPa})\end{array}$ & $\begin{array}{c}\gamma_{\text {max }} \\
(\%)\end{array}$ & $\begin{array}{c}\gamma_{\text {ult }} \\
(\%)\end{array}$ & Sample & $\begin{array}{c}\tau_{\max } \\
(\mathrm{MPa})\end{array}$ & $\begin{array}{c}\gamma_{\text {max }} \\
(\%)\end{array}$ & $\begin{array}{c}\gamma_{\text {ult }} \\
(\%)\end{array}$ \\
\hline URE_1 & 0.099 & 0.0020 & 0.0365 & GRE_1 & 0.099 & 0.0063 & 0.0142 & NRE_1 & 0.093 & 0.0272 & 0.0332 \\
\hline URE_2 & 0.067 & 0.0039 & 0.0304 & GRE_2 & 0.110 & 0.0083 & 0.0343 & NRE_2 & 0.082 & $* *$ & $* *$ \\
\hline URE_3* & 0.080 & $* *$ & $* *$ & GRE_3 & 0.089 & $* *$ & $* *$ & NRE_3 & 0.120 & 0.0344 & 0.0490 \\
\hline $\begin{array}{c}\text { Average } \\
(\text { CoV })\end{array}$ & $\begin{array}{c}0.08 \\
(19 \%)\end{array}$ & 0.003 & 0.034 & Average & $\begin{array}{c}0.10 \\
(10 \%)\end{array}$ & 0.007 & 0.024 & Average & $\begin{array}{c}0.10 \\
(20 \%)\end{array}$ & 0.031 & 0.041 \\
\hline
\end{tabular}

* NRE wallet considered URE as the TRM detached before the test.

** The LVDTs fell off after the elastic behaviour.

The improvement of shear strength is a consequence of the TRM holding the sides split by cracking while the embedded mesh carries a quota of the load. The corresponding shear strain is also enhanced, especially in NRE case, due to the higher deformability of the nylon mesh. At the ultimate stage, the mesh becomes excessively deformed or the bond around the diagonal crack is disrupted, which results in a drop of the shear stress. Figure 3 reports DIC contours of the principal strain at $\gamma_{\tau \max }$ and $\gamma_{u l t}$ for wallets URE_2, GRE_3 and NRE_2. When the shear strength is achieved $\left(\tau_{\max }\right)$, the unstrengthened wallets are characterized by a main crack along the diagonal, which crosses the layers of the rammed earth (Figure 3a). Delamination along the interface of the layers occurs and it is clearly developed at the ultimate state (Figure 3d). The patterns observed in glass fibre reinforced wallets at the peak load are similar to those of URE, nevertheless they showed a wider main crack and local spreading of the deformations (Figure 3b). Such crack patterns and strain distributions are slightly different when compared to the ones presented at the ultimate stage $\left(\gamma_{u l t}\right)$ (Figure 3e); hence, they are deemed to result from local detachment of the TRM nearby the cracks or from sliding of the mesh. The opening of the main crack with onset of delamination between rammed earth layers at peak load is detected in case of NRE as well (Figure 3c), while the strains are broad spread with development of further cracks until the ultimate stage (Figure $3 \mathrm{f}$ ). This fact suggests that the nylon mesh seems to have a higher capacity to distribute the strains through the cracks.

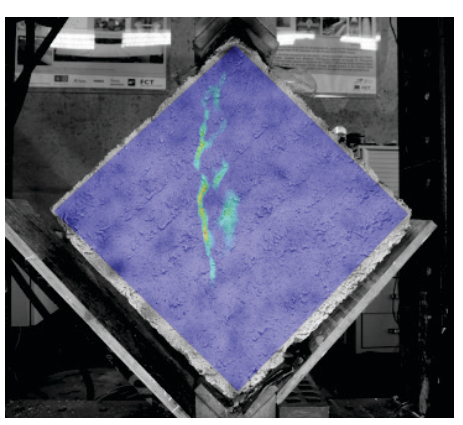

(a)

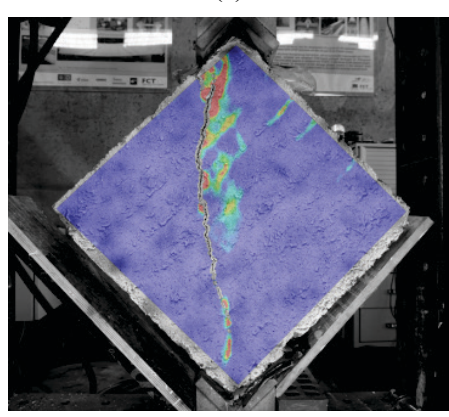

(d)

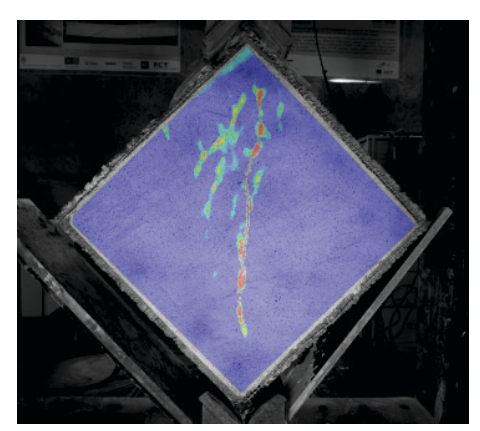

(b)

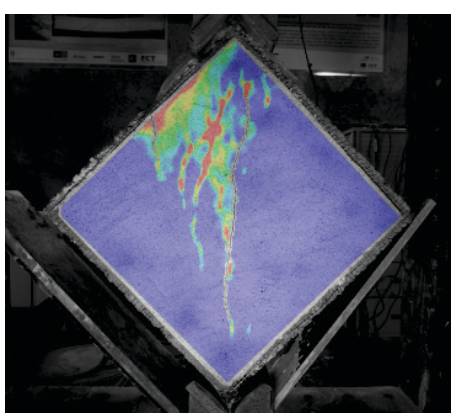

(e)

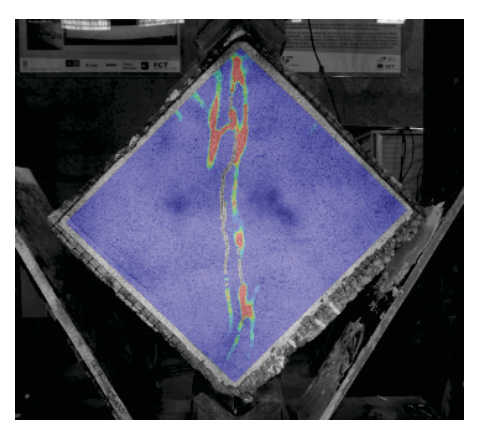

(c)

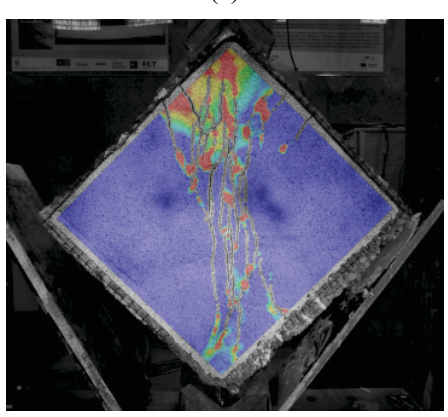

(f)

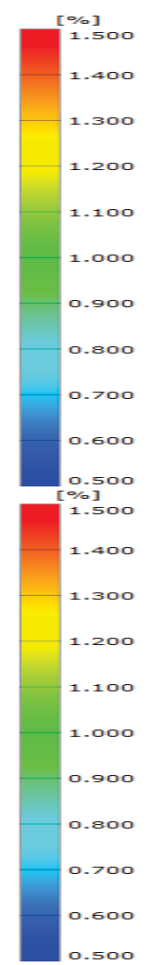

Figure 3. Crack pattern at peak load $\left(\gamma_{\max }\right)$ of (a) URE_2, (b) GRE_3, (c) NRE_2 and at ultimate load $\left(\gamma_{u l t}\right)$ of $($ d) URE_2, (e) GRE_3 and (f) NRE_2 
Since no recommendations for calculating the tangent shear modulus of the rammed earth $(G)$ were found in literature, different linear regressions were performed in ranges of $10 \%$ of $\tau_{\max }$ increased of a $2 \%$ step, using data coming from the LVDTs. Figure 4 reports the $G$ values of each wallet and the corresponding correlation coefficient $\left(R^{2}\right.$ value) as a function of the relative shear stress $\tau / \tau_{\max }$. In general, the shear modulus curve seems to present a constant initial trend. Subsequently, the shear modulus appears to decrease with increasing values of $\tau / \tau_{\max }$, which is consistent with development and opening of cracks that reduce the stiffness of rammed earth. Therefore, the values of $G$ belonging to the constant branch of the curve and having $\mathrm{R}^{2}$ higher than 0.75 were here considered to represent the elastic shear modulus. Finally, those values were selected to calculate the average $G$, average $\mathrm{R}^{2}$ and the corresponding ranges $\tau / \tau_{\max }$ (Table 5). The samples NRE_1 and NRE_2 presented negative shear modulus or low correlation coefficient and were not considered here. The URE wallets are characterized by a low shear modulus with respect to GRE and NRE, because of the tensile capacity of the TRM, though the difference in stiffness is not considerable. It should be noted that it was not possible to find only one range $\tau / \tau_{\max }$ common for all the cases where the shear modulus results reliable, likely due to recording data by the LVDTs.

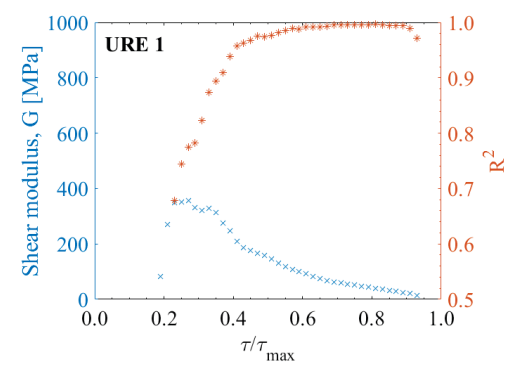

(a)

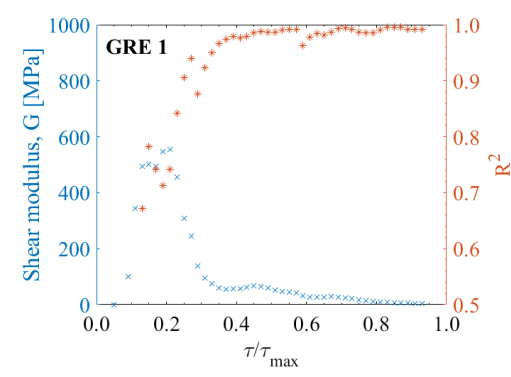

(d)

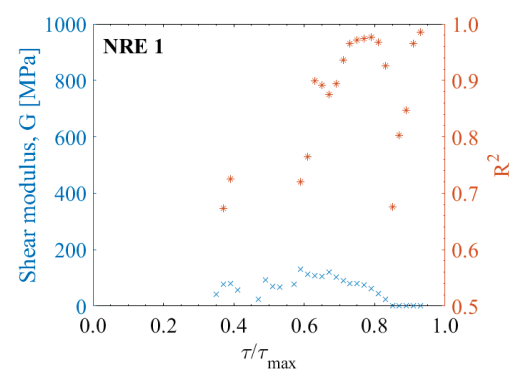

(g)

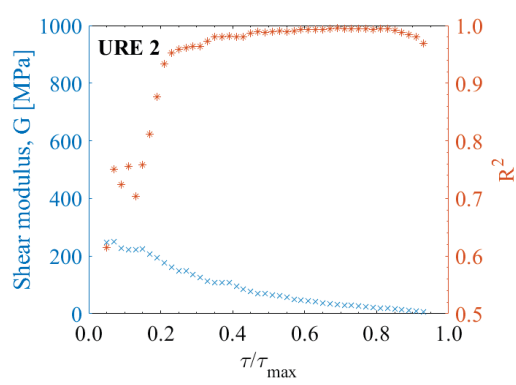

(b)

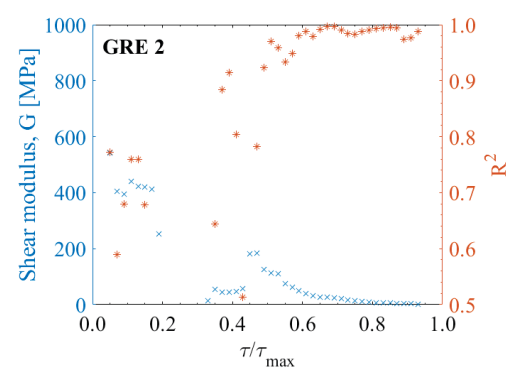

(e)

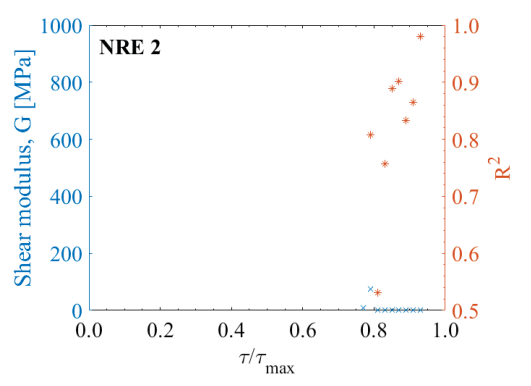

(h)

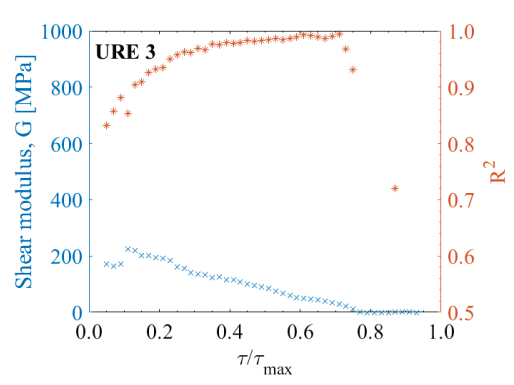

(c)

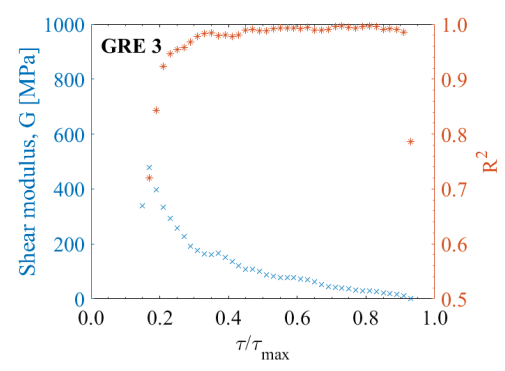

(f)

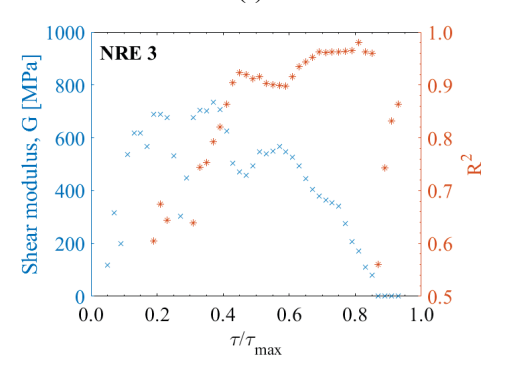

(i)

Figure 4. Tangent shear modulus $(\mathrm{G})$ and corresponding correlation coefficients $\left(\mathrm{R}^{2}\right)$ against the considered range $\tau \tau_{\max }$ for (a) URE_1, (b) URE_2, (c) URE_3, (d) GRE_1, (e) GRE_2, (f) GRE_3, (g) NRE_1, (h) NRE_2 and (i) NRE_3 
Table 5. Average tangent shear modulus $(\mathrm{G})$ and average correlation coefficient $\left(\mathrm{R}^{2}\right)$ according to the considered $\tau \tau_{\text {max }}$ ranges ( $\mathrm{CoV}$ is reported in brackets)

\begin{tabular}{|c|c|c|c|c|c|c|c|c|c|c|c|}
\hline & Range & $\mathrm{G}$ & $\mathrm{R}^{2}$ & & Range & $\mathrm{G}$ & $\mathrm{R}^{2}$ & & Range & $\mathrm{G}$ & $\mathrm{R}^{2}$ \\
\hline URE_1 & $\begin{array}{c}0.20- \\
0.40\end{array}$ & $\begin{array}{c}334 \\
(5 \%)\end{array}$ & $\begin{array}{c}0.82 \\
(7 \%)\end{array}$ & GRE_1 & $\begin{array}{c}0.10- \\
0.28 \\
\end{array}$ & $\begin{array}{c}510 \\
(8 \%)\end{array}$ & $\begin{array}{c}0.76 \\
(7 \%)\end{array}$ & NRE_1 & - & - & - \\
\hline URE_2 & $\begin{array}{c}0.02- \\
0.22\end{array}$ & $\begin{array}{c}226 \\
(6 \%)\end{array}$ & $\begin{array}{l}0.75 \\
(5 \%)\end{array}$ & GRE_2 & $\begin{array}{c}0.00- \\
0.18\end{array}$ & $\begin{array}{c}441 \\
(13 \%)\end{array}$ & $\begin{array}{c}0.71 \\
(11 \%)\end{array}$ & NRE_2 & - & - & - \\
\hline URE_3 & $\begin{array}{c}0.00- \\
0.28\end{array}$ & $\begin{array}{c}192 \\
(11 \%)\end{array}$ & $\begin{array}{l}0.90 \\
(4 \%)\end{array}$ & GRE_3 & $\begin{array}{c}0.14- \\
0.32\end{array}$ & $\begin{array}{c}302 \\
(22 \%)\end{array}$ & $\begin{array}{c}0.92 \\
(5 \%)\end{array}$ & NRE_3 & $\begin{array}{c}0.28- \\
0.46\end{array}$ & $\begin{array}{c}695 \\
(6 \%)\end{array}$ & $\begin{array}{l}0.79 \\
(6 \%) \\
\end{array}$ \\
\hline
\end{tabular}

\section{Conclusion}

A first experimental investigation on the shear behaviour of rammed earth wallets reinforced with a TRM-based compatible technique is here reported. Firstly, each component was characterized, namely soil, rammed earth, earth mortar and two different meshes (glass and nylon). Afterwards, diagonal compression tests were carried out on unreinforced (URE), glass fiber reinforced (GRE) and nylon reinforced $(N R E)$ rammed earth wallets. The enhancement of the shear strength $\left(\tau_{\max }\right)$ for GRE and NRE, with the improvement of the corresponding shear strain $\left(\gamma_{\text {tmax }}\right)$, results from the capacity of the embedded mesh to carry part of the load after rammed earth cracks. The DIC analysis shows similar crack pattern between URE, GRE and NRE wallets at the peak load, while different strain distribution was observed up to the ultimate stage $\left(\gamma_{u l t}\right)$. In fact, NRE walls developed a wide spreading of strains, which evidenced the capacity of the nylon mesh to transfer the stresses through the cracks; whereas local detachment of the TRM was detected in GRE samples. The investigation of shear modulus $(G)$ development allowed to observe an initial constant trend followed by a decreasing of shear stiffness, which is consistent with the increasing of damage in the rammed earth. Therefore, the values of $\mathrm{G}$ belonging to the constant trend with $\mathrm{R}^{2}$ higher than 0.75 were deemed to represent the shear modulus for those wallets, which resulted higher for GRE and NRE. Even though, it was not possible to define a range $\tau / \tau_{\max }$ common to all the samples for assessing the shear modulus; likely due to recording data by the LVDTs. Based on the achieved results, the proposed TRM-based compatible strengthening is considered a suitable solution for vernacular rammed earth heritage. Further diagonal compression tests will be performed to overcome difficulties related to recording data. Furthermore, in-plane tests on real scale walls will be conducted to investigate the shear behaviour of large rammed earth specimens.

\section{Acknowledgment}

This work was partly financed by FEDER funds through the Operational Programme Competitiveness Factors (COMPETE 2020) and by national funds through the Foundation for Science and Technology (FCT) within the scope of project SafEarth - PTDC/ECM-EST/2777/2014 (POCI-01-0145-FEDER-016737). The support from grants SFRH/BD/131006/2017 and SFRH/BPD/97082/2013 is also acknowledged.

\section{References}

[1] H. Houben, H. Guillaud, Earth construction: a comprehensive guide. London, Intermediate Technology Publication, 2008.

[2] R.A. Silva, D.V. Oliveira, T. Miranda, N. Cristelo, M.C. Escobar, E. Soares, Rammed earth construction with granitic residual soils: The case study of northern Portugal, Construction and Building Materials, 47 (2013) 181-191.

[3] R.A. Silva, N. Mendes, D.V. Oliveira, A. Romanazzi, O. Domínguez-Martínez, T. Miranda, Evaluating the seismic behaviour of rammed earth buildings from Portugal: from simple tools to advanced approaches. Engineering Structures, 157 (2018) 144-156.

[4] M. Correia, Rammed earth in Alentejo. Lisbon, Argumentum, 2007. 
[5] T.T. Bui, Q.B. Bui, A. Limam, S. Maximilien, Failure of rammed earth walls: From observations to quantifications. Construction and Building Materials, 51 (2014) 295-302.

[6] K. Liu, M. Wang, Y. Wang, Seismic retrofitting of rural rammed earth buildings using eternally bonded fibers. Construction and Building Materials, 100 (2015) 91-101.

[7] A.A. Costa, H. Varum, H. Rodrigues, G. Vasconcelos, Seismic behaviour analysis and retrofitting of a row building. In Correia M., Lourenço P.B., Varum H., Seismic Retrofitting: Learning from vernacular architecture. London, Taylor and Francis Group, 2015.

[8] G. De Felice, S. De Santis, L. Garmendia, B. Ghiassi, P. Larringa, P.B. Lourenço, D.V. Oliveira, F. Paolacci, C.G. Papanicolaou, Mortar-based systems for externally bonded strengthening of masonry. Materials and Structures, 47 (2014) 2021-2037.

[9] B. Ghiassi, G. Marcari, D.V. Oliveira, P.B. Lourenço, Numerical analysis of bond behavior between masonry bricks and composite materials. Engineering Structures, 43 (2012) 210- 220.

[10] L. Righetti, V. Edmondson, M. Corradi, A. Borri, Fiberglass grids as sustainable reinforcement of historic masonry. Materials, 9 (2016) 1-17.

[11] J. Vargas, M. Blondet, F. Ginocchio, G. García, 35 Años de investigaciones en sismo adobe: la tierra armada, International Conference SismoAdobe 2005: architecture, construction and conservation of earthen buildings in seismic areas, Lima, 2005.

[12] T.L.G. Michiels, Seismic retrofitting techniques for historic adobe buildings. International Journal of Architectural Heritage, 9 (2014) 1059-1068.

[13] A. Figueiredo, H. Varum, A. Costa, D. Silveira, C. Oliveira, Seismic retrofitting solution of an adobe masonry wall. Materials and Structures, 46 (2013) 203-219.

[14] Y. Wang, M. Wang, K. Liu, W. Pan, X. Yang, Shaking table tests on seismic retrofitting of rammed earth structures. Bulletin of Earthquake Engineering, 3 (2017) 1037-155.

[15] M. Fagone, F. Loccarini, G. Ranocchiai, Strength evaluation of jute fabric for the reinforcement of rammed earth structures. Composites Part B: Engineering, 133 (2017) 1-13.

[16] K. Van Balen, I. Papayianni, R. Van Hees, L. Binda, A. Waldum, Introduction to requirements for and functions and properties of repair mortars. RILEM TC 167-COM: 'Characterisation of Old Mortars with Respect to their Repair'. Materials and Structures, 38 (2005) 781-785.

[17] L. Miccoli, D.V. Oliveira, R.A. Silva, U. Müller, L. Schueremans, Static behaviour of rammed earth: experimental testing and finite element modelling. Materials and Structures, 48 (2015) 3443-3456.

[18] D.V. Oliveira, R.A. Silva, C. Barroso, P.B. Lourenco, Characterization of a compatible low cost strengthening solution based on the TRM Technique for Rammed Earth. Key Engineering Materials, 747 (2018) 150-157.

[19] A. Romanazzi, D.V. Oliveira, R.A. Silva, A TRM-based compatible strengthening solution for rammed earth heritage: investigation of the bond behavior. In proc. of SAHC2018, International Conference of Structural Analysis of historical Construction, Cusco, Peru, 2018.

[20] M. Van Gorp, Experimental study of in-plane behaviour of rammed earth strengthened with TRM. MsC thesis, KU Leuven, 2018.

[21] GOM Correlate 2018 Software Digital Image Correlation.

[22] ASTM E519, Standard test method for diagonal tension (shear) in masonry assemblages, 2002. 